\title{
Exploring the path from idea generation till knowledge creation
}

\author{
Sonal Chaudhary \\ Alumni, KIET School of Management, KIET \\ Group of Institutions, Delhi-NCR, Ghaziabad \\ Lucknow, India
}

\begin{abstract}
In the present era of Modernization and technology advancement, almost everything has evolved. But what we have witnessed is that something remains the same. One such thing is idea we are surrounded by ideas we may not realize but this modernization globalization is all due to some extra ordinary ideas.it can be a sword if we work hard for it or it can make you feeble. This is to strengthen over knowing about idea. How to use them, how to focus on them etc.

Index Terms-Talent, Knowledge, Idea, Path Creation, Relationship
\end{abstract}

\section{INTRODUCTION}

I $\mathrm{N}$ THE present era of Modernization and technology advancement, almost everything has evolved around three things: idea, talent and Knowledge.

\section{A. Idea}

Idea can be defined as one or more thoughts that come in one's mind. Ideas may be useful or useless. Ideas can show us path for better opportunities. And good opportunities shape one's life and future.

\section{B. Talent}

Unique way, or we can put it this way, talent differentiates one person from the other. It is not true that only an educated person is talented, there are lot of people who don't possess any degree or any certificate, but they are still talented, as they got some skill, which makes them talented.

\section{Knowledge}

Information, understanding, awareness that has been obtained by experience or study is known as knowledge.

Knowledge is the important tool to survive in the era of throat cut competition and survive and create a position of themselves in the world of digitalization.

Knowledge can be helpful in all the fields like Information Technology, Manufacturing, teaching, Academics, Engineering, Medicine, Pharmaceutical, Entrepreneurship and Start ups etc.

Figure 1 represent the path of idea generation till knowledge creation which is represented below:

\section{LITERATURE REVIEW}

Great ideas lead to great opportunities and vice versa. Ideas are responsible for the prosperity as well as downfall of humans but without one we would still be living in prehistoric times. No idea is too small as all sorts of ideas have

\author{
Meenakshi Tyagi \\ Assistant Professor, \\ KIET School of Management, KIET Group of \\ Institutions, Delhi-NCR, Ghaziabad, \\ meenakshi.tyagi@kiet.edu
}

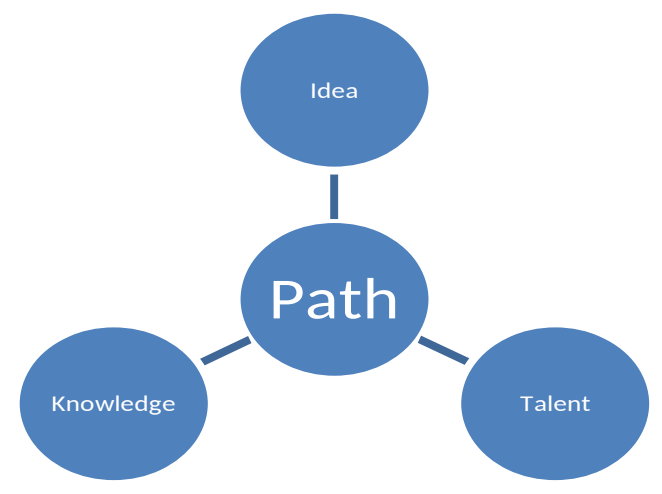

Fig. 1. Path of Exploration

potential to change the world. Now, above written can be sum up as:

1. Idea may be innovative.

2. Idea may be creative.

3. Idea may lead to a plan, thought or suggestion, especially about what to do in a particular situation.

4. Idea may be a concept developed by the mind.

For example, Start-Up India. Start-up India is a flagship initiative of the Government of India, intended to catalyse Start-up culture and build a strong and inclusive ecosystem for innovation and entrepreneurship in India. Since the launch of the initiative on 16th January, 2016, Start-up India has rolled out several programs with the objective of supporting entrepreneurs, and transforming India into a country of job creators instead of job seekers. It was a tremendous as well as legendary idea which with proper execution resulted in platform for other revolutionary ideas which may lead to employment etc.

Now, there are certain questions that come to our mind when we talk about an idea.

1. What is an idea?

2. What sorts of ideas are their?

3. And how to explain them once $\mathrm{u}$ have them?

\section{PROPOSED WORK}

Let's understand them all together.

1. The word "idea" comes into play to describe thoughts and suggestions. For example- I have an idea, let's eat Pizza at Dominos for lunch. 
2. We use the word "idea" to describe new concepts. For example- I have an idea - Lets prepare a machine that washes and dries our cloths automatically.

3. Also, we use the word "idea" when someone says something stupid. For example- You have no idea.

If we focus on the first two examples, the word "Idea" telegraphs that something new is coming. And in third one, it is just the word play.

One of the important aspects to having an idea is how to explain that to others. Hence, one must acquire ability to explain an idea. As when you know how to explain your ideas, your working life will improve. An idea needs to be explained with utmost ease, one need to be fully confident about the same. One should be fully comfortable about it so that others can feel the same. And use of the simple and mass communication skills is must. If it makes it easy, interesting then it may be with the help of Audio and Visual Aids. Thus, having an idea is not enough but you need certain talent to nurture it, develop it so that it may be fruitful. Which leads to our next big thing i.e. What is talent?

It is not true that only an educated person is talented, there are lot of people who don't possess any degree or any certificate, but they are still talented, as they got some skill, which makes them talented. For example- Maker of Lijjat Papad Franchise, which is run by a group of household's ladies, who are making millions. So, it is just the right use of skill set which makes you talented. Now, the question arises is can we acquire talent?

Talent is not something which is inherited in a person and but it is a skill that is developed by doing hard work, learning, practicing etc. in a span of time. When such skill nurtures and becomes fruitful, we may call that person talented. When we skillfully learn something and produce it the same way, we acquire that talent. Also, one can learn a skill, but converting it on an opportunity requires hard work, discipline, and practice.

Information, understanding, awareness that has been obtained by experience or study is known as knowledge.

Knowledge is valuable treasure which is gifted from our inner spirit which becomes the source of life. When we are born, all of us are same. Whether one is going to become a saint or a scientist, no one knows but it all depends on the knowledge, life experiences we acquire and resources we had to do so. A dead man got none- no life, no power and no knowledge. It is said that knowledge is divine gift that accompanies the spirit which is infused into a person between conception and birth. And, the spirit that is the life source. Without it, there is no life and no knowledge.

Knowledge is the mental grasp of the reality. It is awareness of the identity of aspects of the same. Several times, it has been implied that the "KNOWLEDGE IS THE GREATEST VIRTUE"

Now, question arises is how to acquire it? Well it is simple, Knowledge is everywhere, and we can acquire it in many ways:
- We can get knowledge from children as well as elders.

-We can get knowledge from the societies.

- We can get knowledge from Schools, Colleges and University.

- We can get knowledge from our families.

- We can get knowledge from our farmers, workers etc.

- We can get knowledge from the Electronic media i.e. $\mathrm{TV}$, Radio, Computers, Internet etc.

- We can get knowledge from print media i.e. Newspapers, Magazines etc.

- We can get knowledge from libraries.

- We can get knowledge from surroundings.

- We can get knowledge from travelling, going places etc.

\section{FUTURE WORK}

Future work plays a vital role in any research as it suggests the future scope of a research. Talking about idea generation, a good idea leads to - establishing a new Business; Business generates revenue and employment opportunities to people, which further leads to the growth of the society; Eventually, it leads to growth and GDP increase of the country.

On the other hand, Knowledge helps the idea to grow and flourish it in a right direction. it provides new way to do any work, which leads to better results.

\section{CONCLUSION}

Exploring the path from idea generation to creation of knowledge has many aspects related to it. An idea is a thought that comes to a person's mind based on his understanding, awareness, thought process, conception or notion which may lead to an innovative product or output, that help people to ease their life. though, just having an idea is not enough, instead it requires inner talent of idea or to transform the idea productively. Talent could be naturally inherited or can be developed with time.

Knowledge means information, awareness or awareness which is obtained by study or live experiences. We can get knowledge from a child as well as an adult or from school or college or from social media. Knowledge is present everywhere, but it depends on you that how you will grasp it.

For example: Startup India is one of the initiative of Indian government, that focuses on promoting innovation and entrepreneurship. To be a part of this initiative, entrepreneur needs to have an idea, which is backed up by inner talent and knowledge around that domain.

Hence, We can say that idea generation is the first thing that comes to one's mind, and its level depends on the talent and knowledge of an individual.

\section{REFERENCES:}

[1] Agarwal, S., Jindal, A., Garg, P., \& Rastogi, R. (2017). The influence of quality of work life on trust: empirical insights from a SEM application. International Journal of Indian Culture and Business Management, 15(4), 506-525. 
[2] Agarwal, S., Garg, P., \& Rastogi, R. (2011). Impact of Quality of Work Life on Employee Trust. International Journal of Management Research, 54.
[3] http://Www.virgin.com

[4] http://Historyofislam.com 